\title{
A Transdermal Measurement Platform Based on Microfluidics
}

\author{
Wen-Ying Huang, ${ }^{1}$ Jung-Ping Huang, ${ }^{1}$ Chia-Ching Lin, ${ }^{1}$ and Yung-Sheng Lin ${ }^{2}$ \\ ${ }^{1}$ Department of Applied Cosmetology and Master Program of Cosmetic Science, Hungkuang University, Taichung 43302, Taiwan \\ ${ }^{2}$ Department of Chemical Engineering, National United University, Miaoli 36063, Taiwan \\ Correspondence should be addressed to Yung-Sheng Lin; linys@nuu.edu.tw
}

Received 21 September 2017; Accepted 3 December 2017; Published 25 December 2017

Academic Editor: Lorena Tavano

Copyright (C) 2017 Wen-Ying Huang et al. This is an open access article distributed under the Creative Commons Attribution License, which permits unrestricted use, distribution, and reproduction in any medium, provided the original work is properly cited.

\begin{abstract}
The Franz diffusion cell is one of the most widely used devices to evaluate transdermal drug delivery. However, this static and nonflowing system has some limitations, such as a relatively large solution volume and skin area and the development of gas bubbles during sampling. To overcome these disadvantages, this study provides a proof of concept for miniaturizing models of transdermal delivery by using a microfluidic chip combined with a diffusion cell. The proposed diffusion microchip system requires only $80 \mu \mathrm{L}$ of sample solution and provides flow circulation. Two model compounds, Coomassie Brilliant Blue G-250 and potassium ferricyanide, were successfully tested for transdermal delivery experiments. The diffusion rate is high for a high sample concentration or a large membrane pore size. The developed diffusion microchip system, which is feasible, can be applied for transdermal measurement in the future.
\end{abstract}

\section{Introduction}

Transdermal drug delivery has been a topic of considerable research in the field of pharmaceuticals for decades [1]. Current and future prospects of transdermal drug delivery have been reviewed thoroughly in many articles. [2-4]. Transdermal delivery is an extremely attractive and innovative route through which drugs exert systemic effects [4]. It has benefits such as avoiding first-pass metabolism, sustained therapeutic action, and greater patient compliance; thus, it is a potential noninvasive route for drug administration [5].

The Franz diffusion cell is one of the most accepted models for transdermal study [6-9]. The Franz diffusion cell is a static and nonflowing system [10]. To extend its applications, various improvements have been proposed. A flow-through cell with an automatic fraction collector saved time and labor compared with the conventional Franz cell [11]. Sequential injection chromatography coupled with the Franz cell was developed for the separation and simultaneous determination of two substances in a topical pharmaceutical formulation [12]. However, the Franz diffusion cell still has some limitations such as the requirement of a relatively large solution volume and a large skin area. During sampling, gas is often generated between the donor and receptor and interferes with the transdermal diffusion.
Microfluidic tools offer several advantages over conventionally sized systems. In recent years, microfluidic chips have become a frequently employed platform for the development of new methods and products and are widely used in diverse areas such as medical research [13-15], environmental monitoring [16], chemical analysis [17-21], and biotechnology [22-27]. Microfluidic chip is an engineering technique that integrates several processes including injection, mixing, separation, and transportation in a tiny chip. This method has several advantages, namely, low cost, low volume, low reagent consumption, and fast operation [28-30].

This paper proposes a transdermal delivery system with a microfluidic chip for simple, fast, and low-volume sample detection. Two model compounds, Coomassie Brilliant Blue G-250 and potassium ferricyanide, were tested in this platform. This diffusion microchip system can be applied for evaluating transdermal delivery in the future.

\section{Materials and Methods}

2.1. Development of the Diffusion Microchip. The diffusion microchip (Figure 1) comprises six layers, of which layers (i), (ii), (iv), and (vi) are conventional polymethylmethacrylate substrates constructed by a $\mathrm{CO}_{2}$ laser machine, and (iii) 


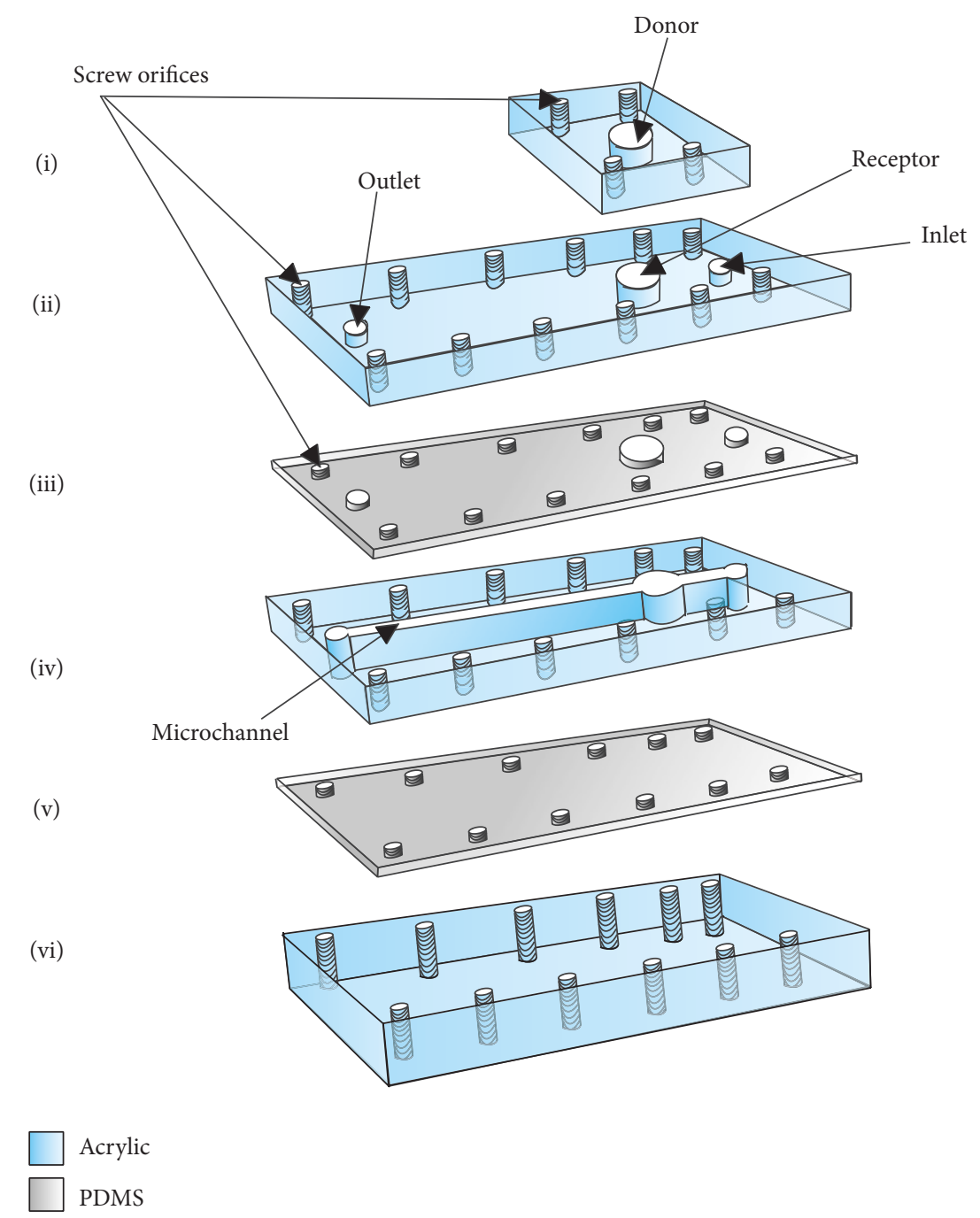

FIGURE 1: Expanded view of the diffusion microchip device. The top layer has a sample donor and the second layer contains the receptor and inlet/outlet. The main channel layer provides circulating flow that transports targets for measurement.

and (v) are polydimethylsiloxane (PDMS) films. The top layer, layer (i), has dimensions of $25.0 \mathrm{~mm} \times 25.0 \mathrm{~mm}$, a sample donor (diameter/depth: $8.0 \mathrm{~mm} / 2.0 \mathrm{~mm}$ ), and four screw orifices. Layers (ii) and (vi) are clamp layers with thicknesses of $2.0 \mathrm{~mm}$ and $4.0 \mathrm{~mm}$, respectively. Layer (iv) is the main channel layer for microfluidics and is $2.0 \mathrm{~mm}$ thick. The receptor has the same size as the donor, and the diameters of the inlet and outlet are $2.0 \mathrm{~mm}$. The length, width, and depth of the main microchannel are $60.0,1.0$, and $2.0 \mathrm{~mm}$, respectively. The PDMS film, which contains 15 holes for the receptor, inlet/outlet, and 12 screw orifices, is applied to prevent leakage of liquid from the microchannel. Figure 2 shows the composition of the diffusion microchip device. First, layers (ii)-(vi) in Figure 1 are connected with eight screws (diameter/pitch: $2 / 8 \mathrm{~mm}$ ) to construct the receptor part. After the membrane is inserted, the top layer providing the donor site and the receptor part are connected with another four screws to form the diffusion microchip device.
2.2. Setup of the Diffusion Microchip System. As shown in Figure 3, the experimental system is comprised of a diffusion microchip, a solution reservoir, and a peristaltic pump (PS103, YOTEC, Hsinchu, Taiwan). A tube (Tygon E-3603 Tubing, Saint-Gobain, Aurora, USA) was installed at the inlet and outlet and then fed through the peristaltic pump to the solution reservoir ( $15 \mathrm{~mL}$ centrifuge tube). The solution was driven by the peristaltic pump, slowly entered the diffusion microchip through the inlet entrance (red line in Figure 3), and proceeded to the microchannel. The outflow exited through the outlet (blue line in Figure 3) and was conveyed through the peristaltic pump to the solution reservoir for further circulation.

The diffusion solution $(80 \mu \mathrm{L})$ was loaded into the donor cell and covered with Parafilm ${ }^{\circledR} \mathrm{M}$ (Sigma, St. Louis, USA) to prevent evaporation. At predetermined time points, $200 \mu \mathrm{L}$ of the solution was collected from the reservoir for detecting the sample concentration by using an absorbance reader 


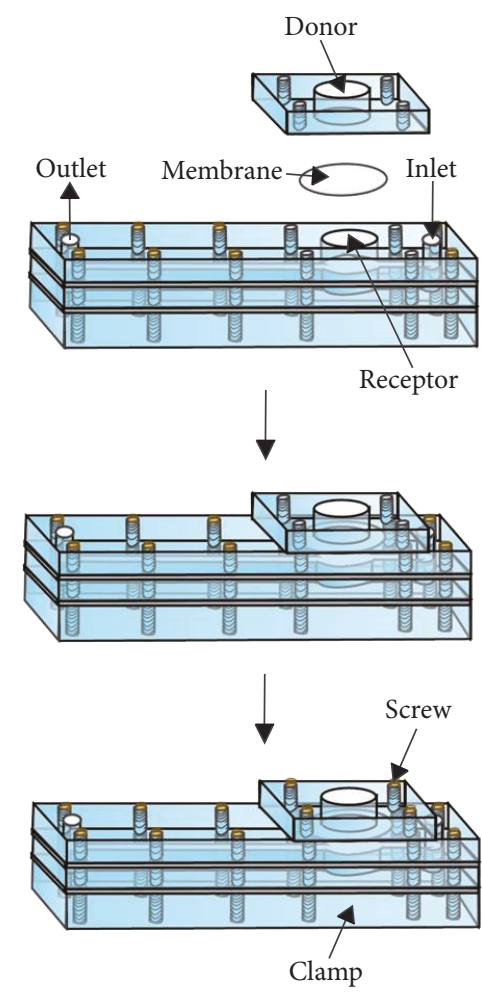

(a)
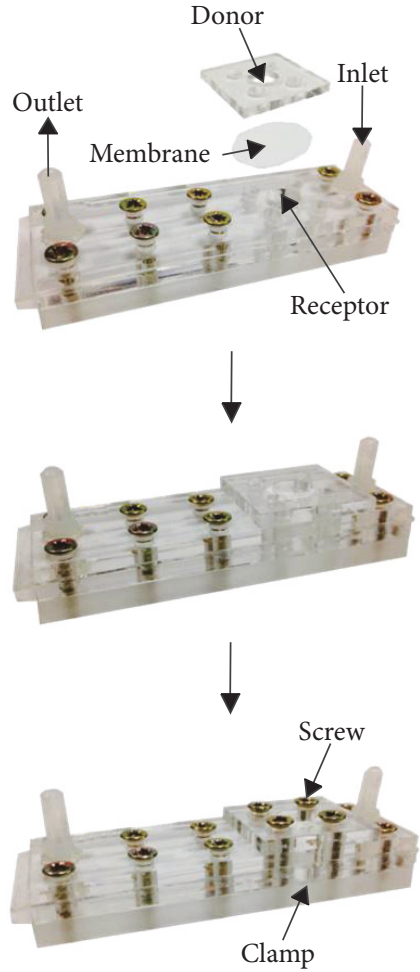

(b)

FIGURE 2: Composition of the diffusion microchip device: (a) schematic and (b) photograph.

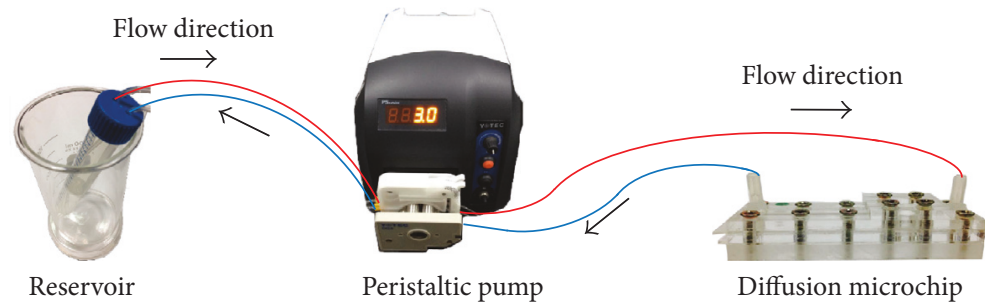

FIGURE 3: Schematic of the setup of the diffusion microchip system for evaluating transdermal delivery.

(Sunrise $^{\mathrm{TM}}$ ELISA, Tecan, Zürich, Switzerland). After measurement, the solution was returned to the reservoir to maintain a fixed flow volume.

2.3. Effectiveness of the Diffusion Microchip System. To test the feasibility of this diffusion microchip system, Coomassie Brilliant Blue G-250 (Bionovas, Toronto, Canada) and potassium ferricyanide (Merck, Darmstadt, Germany) were selected, respectively, as model color compounds for observing molecular diffusion through the donor cell into the receptor and sequential flow in the microchannel. As shown in Figure 3, a membrane with a $5.00 \mu \mathrm{m}$ pore size (Nylon, Toson, Hsinchu, Taiwan) was placed between the receptor and donor and fixed with four screws. A combination of $80 \mu \mathrm{L}$ of $1 \%$ Coomassie Brilliant Blue G-250 and potassium ferricyanide was used as the diffusion solution. At predetermined time points, $1 \mathrm{~mL}$ of solution in the reservoir was collected for examination by using a UV-visible spectrophotometer (V-630, JASCO, Tokyo, Japan). After examination, the solution was returned to the reservoir to maintain a fixed solution volume.

\subsection{Transdermal Drug Delivery}

2.4.1. Effects of the Membrane Pore Size. Three membrane pore sizes, $0.10,0.45$, and $5.00 \mu \mathrm{m}$, were tested on this platform; $80 \mu \mathrm{L}$ of $1.2 \%$ potassium ferricyanide in deionized water was used as the diffusion solution. At predetermined time points, $200 \mu \mathrm{L}$ of the solution was collected from the reservoir to detect the sample concentration by using an absorbance reader at $420 \mathrm{~nm}$. The solution was returned to the reservoir after the assay.

2.4.2. Effects of the Sample Concentration. Potassium ferricyanide solution $(80 \mu \mathrm{L})$ at three concentrations in deionized 
TABLE 1: Size difference between the traditional transdermal drug delivery and diffusion microchip system.

\begin{tabular}{lccc}
\hline Method & Device size (length $\times$ width $\times$ height, $\mathrm{cm})$ & Membrane size $(\mathrm{mm})$ & Injection volume $(\mathrm{mL})$ \\
\hline Franz diffusion cell & $11.0 \times 2.4 \times 8.6$ & 25 & 1.00 \\
Diffusion microchip & $7.5 \times 2.4 \times 1.2$ & 10 & 0.08 \\
\hline
\end{tabular}

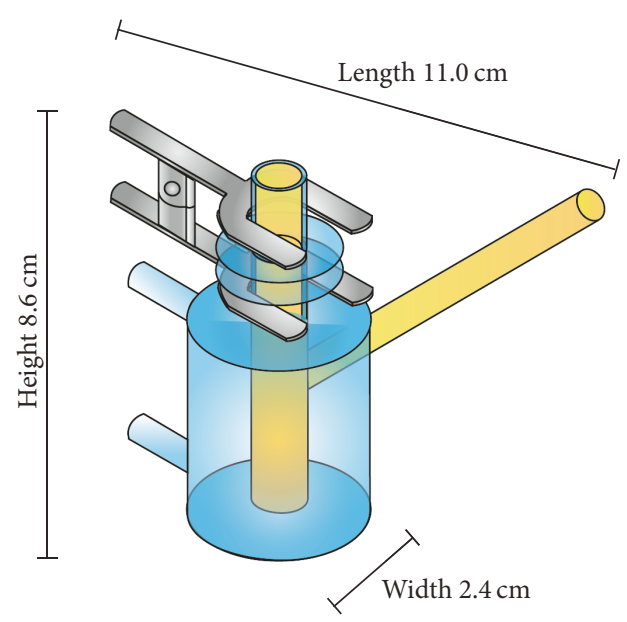

(a)

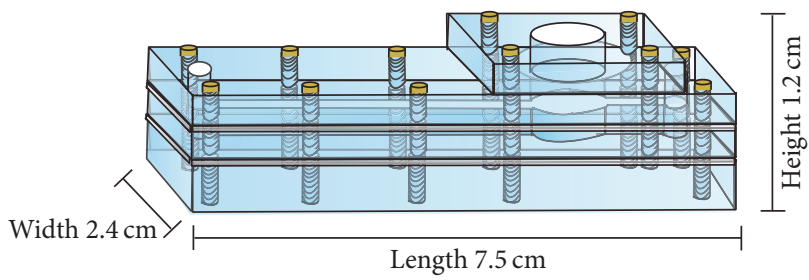

(b)

Figure 4: Device size of (a) Franz diffusion cell; (b) diffusion microchip.

water, $0.4 \%, 0.8 \%$, and $1.2 \%$, was used as the diffusion solution in this experiment. The membrane pore size was $5.00 \mu \mathrm{m}$. The other procedures were the same as those described in Section 2.4.1.

\section{Results and Discussion}

3.1. Characteristics of the Diffusion Microchip. The Franz diffusion cell is one of the most commonly used models for in vitro transdermal studies. The Franz diffusion cell measures $11.0,2.4$, and $8.6 \mathrm{~cm}$ in length, width, and height, respectively (Table 1 and Figure 4(a)). The membrane used in this device is $25 \mathrm{~mm}$ in diameter. The diffusion microchip developed in this study is relatively small. The length, width, and height of the chip are $7.5,2.4$, and $1.2 \mathrm{~cm}$, respectively (Table 1 and Figure 4(b)). The membrane in the chip has a diameter of only $10 \mathrm{~mm}$. Furthermore, the required injection solution volume for diffusion is only $80 \mu \mathrm{L}$. Compared with the Franz diffusion cell, the diffusion microchip considerably reduces the sample and skin material requirements.

As shown in Figure 5, the diffusion microchip can circulate the sample by using the peristaltic pump; however, the sample is stirred using a magnet in the Franz diffusion cell. Figure 5 illustrates sample diffusion through a membrane and its circulation in the microchannel. This system can stimulate transdermal drug delivery with blood circulation in vivo. Sampling is performed in the solution reservoir outside the chip, and no bubbles occur during sampling. Thus, the source of error source in the Franz diffusion cell is eliminated.
3.2. Verification of the Diffusion Microchip System. The diffusion of Coomassie Brilliant Blue G-250 and potassium ferricyanide was tested in the diffusion microchip system. In accordance with previous reports [31-33], Coomassie Brilliant Blue G-250 exhibited maximum absorption at approximately $595 \mathrm{~nm}$, as shown in Figure 6. Furthermore, no signal was detected in the circulating deionized water at the initial time. As time passed, the sample concentration in the solution reservoir increased, indicating continuous diffusion of Coomassie Brilliant Blue G-250 through the membrane.

According to a previous study [34], potassium ferricyanide has an absorption peak at $424 \mathrm{~nm}$, as shown in Figure 7. At the initial time, no absorbance was observed in the tested sample. The absorbance at approximately $424 \mathrm{~nm}$ in the solution increased with diffusion time. After $5 \mathrm{~h}$, there was nearly no change in the absorbance curve.

\subsection{Evaluation of Transdermal Drug Delivery}

3.3.1. Effects of the Membrane Pore Size. Figure 8 shows the effects of the membrane pore size on transdermal delivery for $1.2 \%$ potassium ferricyanide solution. Regardless of the membrane pore size, the absorption value at $424 \mathrm{~nm}$ increased with diffusion time. When the absorbance reached a plateau, the diffusion of potassium ferricyanide was complete. The smaller the pore size of the membrane, the smaller the value of the absorbance increase and the longer the time required for the absorbance to reach the plateau. The total time for the diffusion process was approximately $4 \mathrm{~h}, 5.5 \mathrm{~h}$, and $7 \mathrm{~h}$ for pore sizes of $5.00,0.45$, and $0.10 \mu \mathrm{m}$, respectively. 


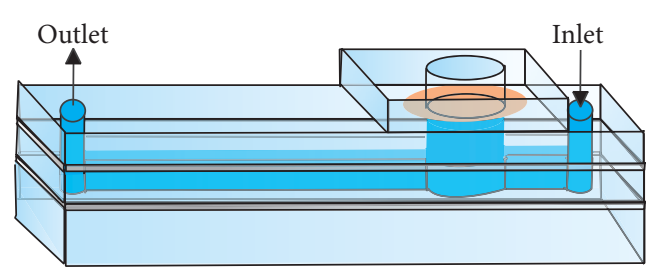

(a)

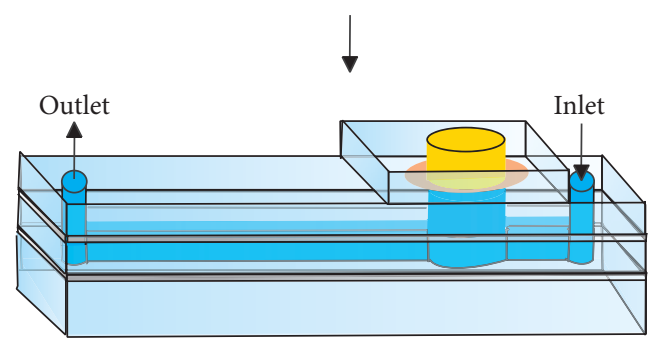

(b)

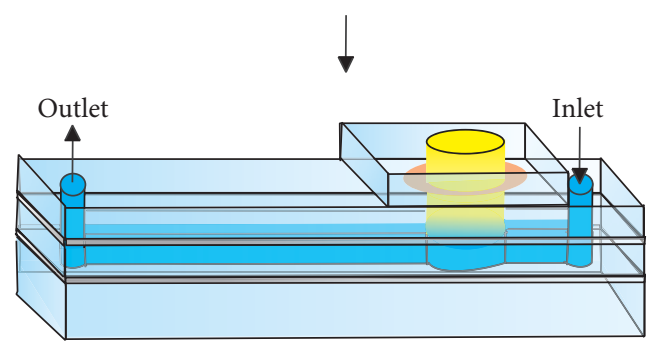

(c)

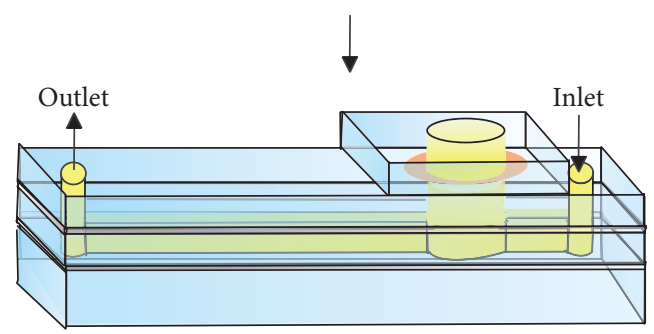

(d)

\begin{tabular}{l|l} 
Acrylic & Deionized water \\
PDMS & Sample \\
Membrane &
\end{tabular}

FIGURE 5: Illustration of diffusion microchip with the diffusion process. (a) No sample added; (b) sample added to donor; (c) sample diffusion through the membrane; (d) sample circulation in the microchannel.

3.3.2. Effects of the Sample Concentration. Figure 9 shows the effects of the sample concentration on transdermal delivery. Three potassium ferricyanide concentrations, $0.4 \%, 0.8 \%$, and $1.2 \%$, were compared with the membrane pore size fixed at $5 \mu \mathrm{m}$. The results indicate that the diffusion rate was higher at a higher concentration of potassium ferricyanide. The time to reach the concentration plateau was shorter at a lower concentration of potassium ferricyanide. The higher the concentration of potassium ferricyanide was, the higher the plateau concentration reached.

\section{Conclusions}

This study proposes a diffusion microchip for evaluating transdermal delivery. Compared with the widely applied Franz diffusion cell, the diffusion microchip system requires 


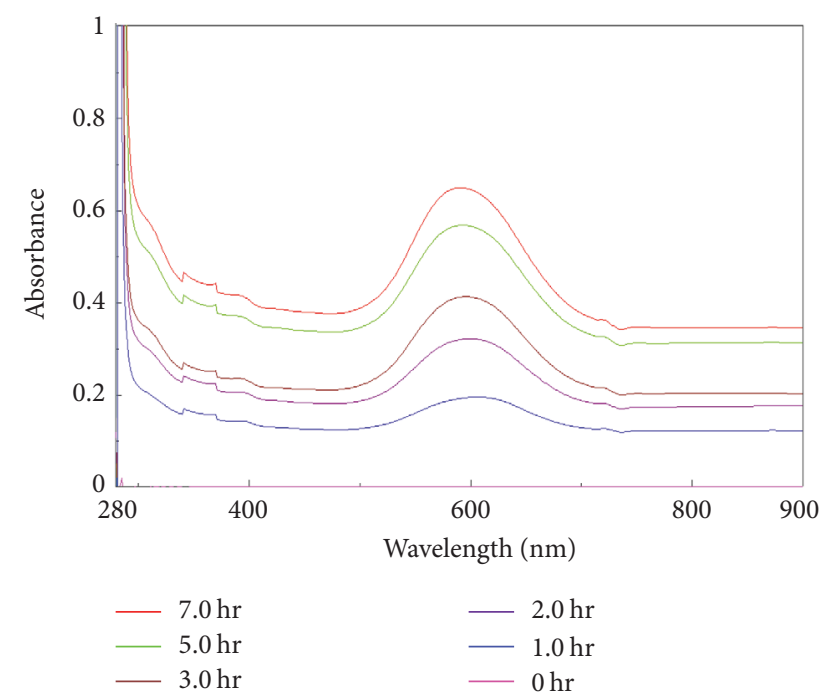

Figure 6: Absorbance curves of Coomassie Brilliant Blue G-250 measured in the solution at different diffusion times. Initially, $1 \%$ Coomassie Brilliant Blue G-250 was used as the diffusion solution in the donor cell.

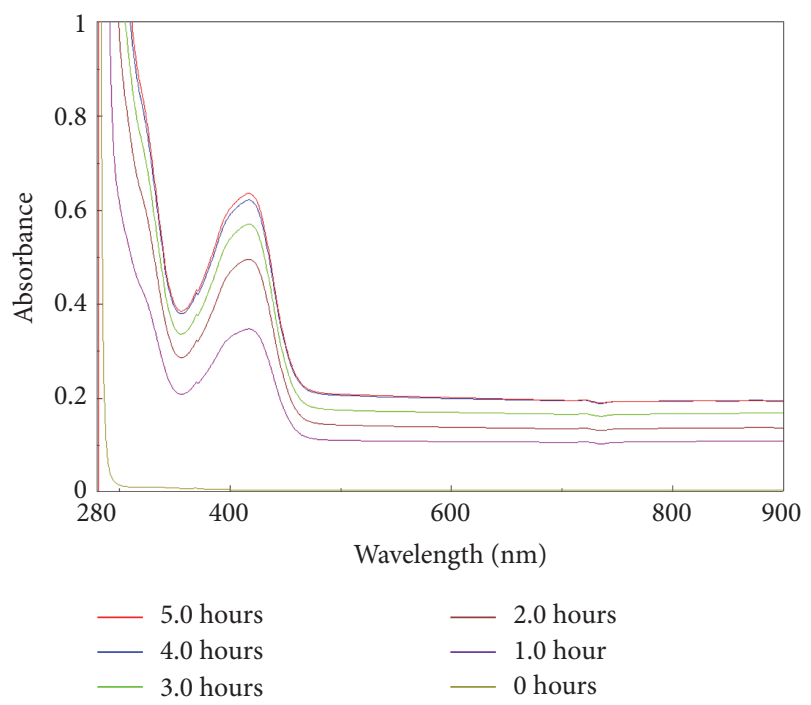

FIGURE 7: Absorbance curves of potassium ferricyanide measured in the solution at different diffusion times. Initially, $1 \%$ potassium ferricyanide was used as the diffusion solution in the donor cell.

a lower volume of sample, and no gas bubbles formed during the experiments. Model compounds, Coomassie Brilliant Blue G-250 and potassium ferricyanide, were used to demonstrate the feasibility of this platform. A high sample concentration or a large membrane pore size resulted in a high diffusion rate. In the future, this diffusion microchip system can be used to determine molecular diffusivity in transdermal delivery.

\section{Conflicts of Interest}

The authors declare no conflicts of interest.

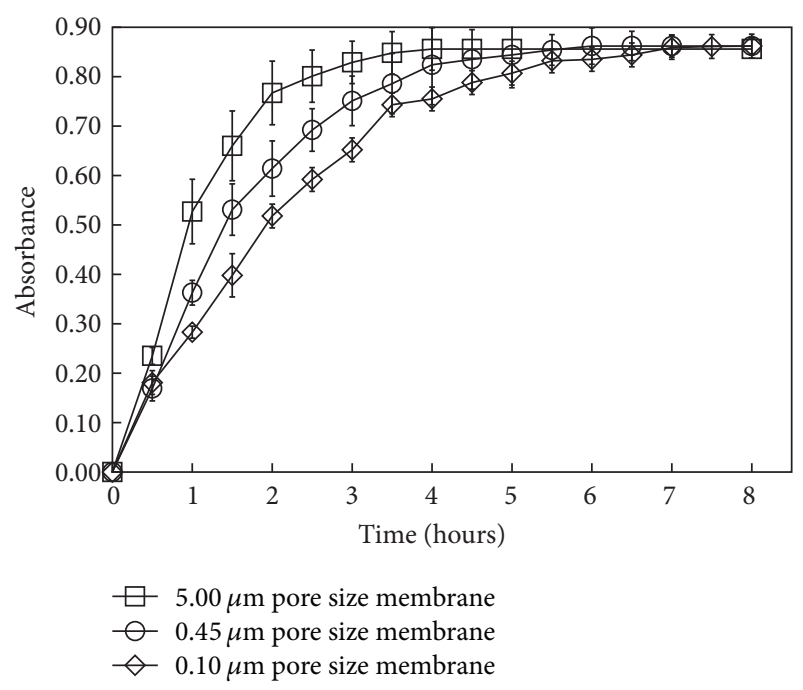

FIGURE 8: Effects of the membrane pore size on transdermal delivery of $1.2 \%$ potassium ferricyanide.

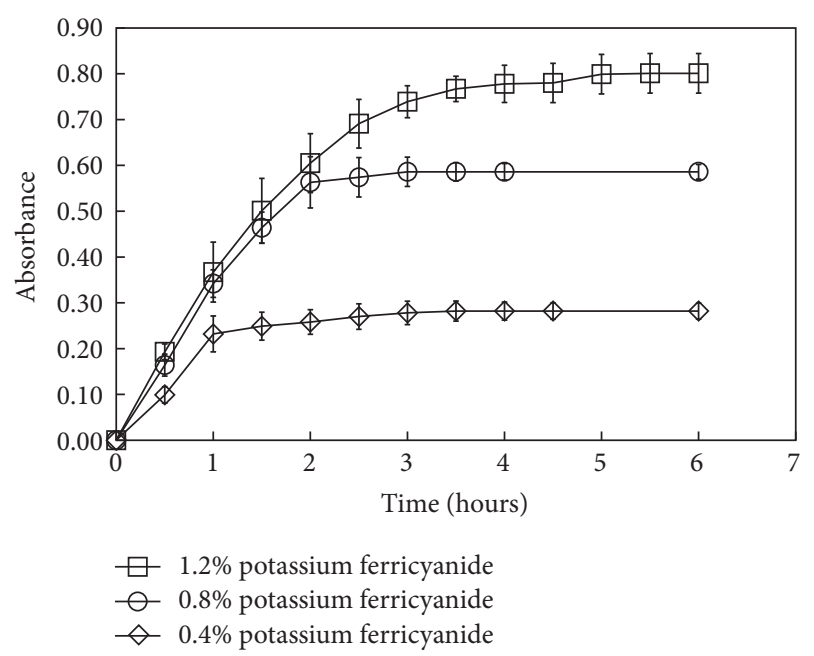

FIGURE 9: Effects of potassium ferricyanide concentration on transdermal delivery with a $5 \mu \mathrm{m}$ membrane pore size.

\section{Authors' Contributions}

Jung-Ping Huang and Chia-Ching Lin conducted the experiments. Wen-Ying Huang performed data analysis and discussions. Yung-Sheng Lin designed the experimental procedure and prepared the manuscript.

\section{Acknowledgments}

This work was supported by the Ministry of Science and Technology, Taiwan, under Grants nos. MOST 106-2221-E239-022 and 105-2627-B-005-002. 


\section{References}

[1] B. C. Palmer and L. A. DeLouise, "Nanoparticle-enabled transdermal drug delivery systems for enhanced dose control and tissue targeting," Molecules, vol. 21, no. 12, article no. 1719, 2016.

[2] E. Larrañeta, M. T. C. McCrudden, A. J. Courtenay, and R. F. Donnelly, "Microneedles: a new frontier in nanomedicine delivery," Pharmaceutical Research, vol. 33, no. 5, pp. 1055-1073, 2016.

[3] J. Chen, Q.-D. Jiang, Y.-P. Chai, H. Zhang, P. Peng, and X.-X. Yang, "Natural terpenes as penetration enhancers for transdermal drug delivery," Molecules, vol. 21, no. 12, article no. 1709, 2016.

[4] B. D. Kurmi, P. Tekchandani, R. Paliwal, and S. R. Paliwal, "Transdermal drug delivery: opportunities and challenges for controlled delivery of therapeutic agents using nanocarriers," Current Drug Metabolism, vol. 18, no. 5, pp. 481-495, 2017.

[5] D. Monti, E. Egiziano, S. Burgalassi et al., "Ionic liquids as potential enhancers for transdermal drug delivery," International Journal of Pharmaceutics, vol. 516, no. 1-2, pp. 45-51, 2017.

[6] T. J. Franz, "Percutaneous absorption. On the relevance of in vitro data," Journal of Investigative Dermatology, vol. 64, no. 3, pp. 190-195, 1975.

[7] M. Crosera, M. Bovenzi, G. Maina et al., "Nanoparticle dermal absorption and toxicity: a review of the literature," International Archives of Occupational and Environmental Health, vol. 82, no. 9, pp. 1043-1055, 2009.

[8] S.-F. Ng, J. J. Rouse, F. D. Sanderson, V. Meidan, and G. M. Eccleston, "Validation of a static franz diffusion cell system for in vitro permeation studies," AAPS PharmSciTech, vol. 11, no. 3, pp. 1432-1441, 2010.

[9] Y. Levintova, F. M. Plakogiannis, and R. A. Bellantone, "An improved in vitro method for measuring skin permeability that controls excess hydration of skin using modified Franz diffusion cells," International Journal of Pharmaceutics, vol. 419, no. 1-2, pp. 96-106, 2011.

[10] L. Bartosova and J. Bajgar, "Transdermal drug delivery in vitro using diffusion cells," Current Medicinal Chemistry, vol. 19, no. 27, pp. 4671-4677, 2012.

[11] W. J. Addicks, G. L. Flynn, and N. Weiner, "Validation of a flowthrough diffusion cell for use in transdermal research," Pharmaceutical Research: An Official Journal of the American Association of Pharmaceutical Scientists, vol. 4, no. 4, pp. 337-341, 1987.

[12] J. Klimundová, D. Šatinský, H. Sklenářová, and P. Solich, "Automation of simultaneous release tests of two substances by sequential injection chromatography coupled with Franz cell," Talanta, vol. 69, no. 3, pp. 730-735, 2006.

[13] F. Piraino, Š. Selimović, M. Adamo et al., "Polyester $\mu$-assay chip for stem cell studies," Biomicrofluidics, vol. 6, no. 4, Article ID 044109, 2012.

[14] H.-H. Hou, Y.-N. Wang, C.-L. Chang, R.-J. Yang, and L.-M. $\mathrm{Fu}$, "Rapid glucose concentration detection utilizing disposable integrated microfluidic chip," Microfluidics and Nanofluidics, vol. 11, no. 4, pp. 479-487, 2011.

[15] E. Biffi, F. Piraino, A. Pedrocchi et al., "A microfluidic platform for controlled biochemical stimulation of twin neuronal networks," Biomicrofluidics, vol. 6, no. 2, Article ID 024106, 2012.

[16] M. Foerster, K. F. Lam, E. Sorensen, and A. Gavriilidis, "In situ monitoring of microfluidic distillation," Chemical Engineering Journal, vol. 227, pp. 13-21, 2013.
[17] K. L. Yeung, X. Zhang, W. N. Lau, and R. Martin-Aranda, "Experiments and modeling of membrane microreactors," Catalysis Today, vol. 110, no. 1-2, pp. 26-37, 2005.

[18] L.-M. Fu and Y.-N. Wang, "Optical microflow cytometer based on external total reflection," Electrophoresis, vol. 33, no. 21, pp. 3229-3235, 2012.

[19] Y.-N. Wang, R.-J. Yang, W.-J. Ju, M.-C. Wu, and L.-M. Fu, "Convenient quantification of methanol concentration detection utilizing an integrated microfluidic chip," Biomicrofluidics, vol. 6, no. 3, Article ID 034111, 2012.

[20] J. S. Zhang, Y. C. Lu, Q. R. Jin, K. Wang, and G. S. Luo, "Determination of kinetic parameters of dehydrochlorination of dichloropropanol in a microreactor," Chemical Engineering Journal, vol. 203, pp. 142-147, 2012.

[21] D. V. Ravi Kumar, B. L. V. Prasad, and A. A. Kulkarni, "Segmented flow synthesis of Ag nanoparticles in spiral microreactor: Role of continuous and dispersed phase," Chemical Engineering Journal, vol. 192, pp. 357-368, 2012.

[22] C.-H. Tsai, H.-H. Hou, and L.-M. Fu, "An optimal threedimensional focusing technique for micro-flow cytometers," Microfluidics and Nanofluidics, vol. 5, no. 6, pp. 827-836, 2008.

[23] K. Ejlebjerg Jensen, P. Szabo, F. Okkels, and M. A. Alves, "Experimental characterisation of a novel viscoelastic rectifier design," Biomicrofluidics, vol. 6, no. 4, Article ID 044112, 2012.

[24] C. Suscillon, O. D. Velev, and V. I. Slaveykova, "Alternating current-dielectrophoresis driven on-chip collection and chaining of green microalgae in freshwaters," Biomicrofluidics, vol. 7, no. 2, Article ID 024109, 2013.

[25] Y. Zeng, M. Shin, and T. Wang, "Programmable active droplet generation enabled by integrated pneumatic micropumps," Lab on a Chip, vol. 13, no. 2, pp. 267-273, 2013.

[26] O. Yesil-Celiktas, S. Cumana, and I. Smirnova, "Silica-based monoliths for enzyme catalyzed reactions in microfluidic systems with an emphasis on glucose 6-phosphate dehydrogenase and cellulase," Chemical Engineering Journal, vol. 234, pp. 166172, 2013.

[27] L.-M. Fu, Y.-N. Wang, and C.-C. Liu, "An integrated microfluidic chip for formaldehyde analysis in Chinese herbs," Chemical Engineering Journal, vol. 244, pp. 422-428, 2014.

[28] D. T. Chiu, A. J. deMello, D. Di Carlo et al., "Small but perfectly formed? successes, challenges, and opportunities for microfluidics in the chemical and biological sciences," Chem, vol. 2, no. 2, pp. 201-223, 2017.

[29] D. Mark, S. Haeberle, G. Roth, F. Von Stetten, and R. Zengerle, "Microfluidic lab-on-a-chip platforms: Requirements, characteristics and applications," Chemical Society Reviews, vol. 39, no. 3, pp. 1153-1182, 2010.

[30] S.-W. Hu, B.-Y. Xu, S. Qiao et al., "A microfluidic cigarette smoke collecting platform for simultaneous sample extraction and multiplex analysis," Talanta, vol. 150, pp. 455-462, 2016.

[31] M. M. Bradford, "A rapid and sensitive method for the quantitation of microgram quantities of protein utilizing the principle of protein dye binding," Analytical Biochemistry, vol. 72, no. 1-2, pp. 248-254, 1976.

[32] J. J. Sedmak and S. E. Grossberg, "A rapid, sensitive, and versatile assay for protein using coomassie brilliant blue G250," Analytical Biochemistry, vol. 79, no. 1-2, pp. 544-552, 1977.

[33] S. Luo, N. B. Wehr, and R. L. Levine, "Quantitation of protein on gels and blots by infrared fluorescence of Coomassie blue and 
Fast Green," Analytical Biochemistry, vol. 350, no. 2, pp. 233$238,2006$.

[34] E. Nalewajko, R. Bort Ramírez, and A. Kojlo, "Determination of dopamine by flow-injection analysis coupled with luminolhexacyanoferrate(III) chemiluminescence detection," Journal of Pharmaceutical and Biomedical Analysis, vol. 36, no. 1, pp. 219223, 2004. 

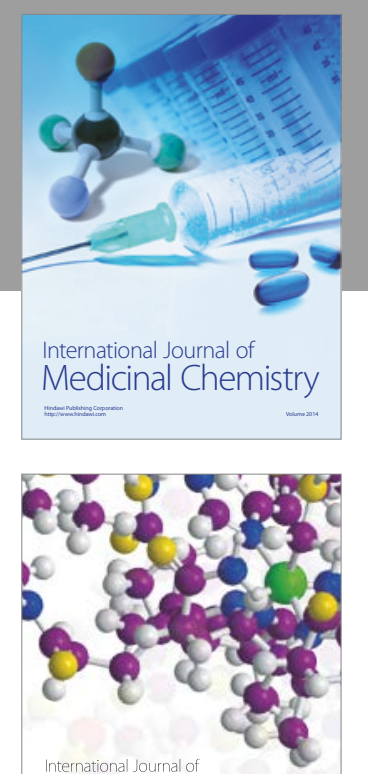

Carbohydrate Chemistry

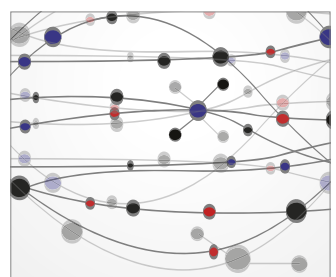

The Scientific World Journal
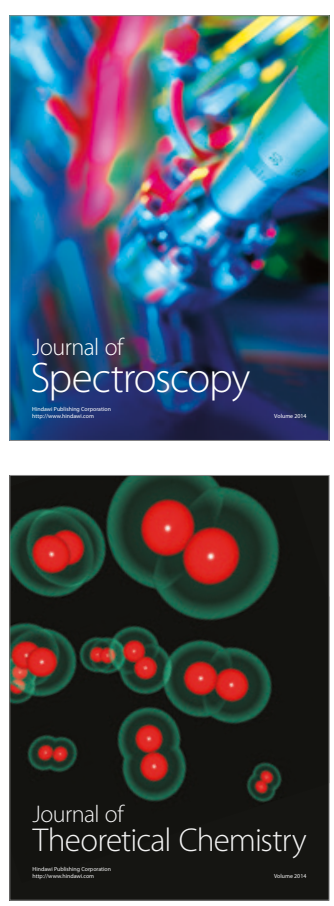
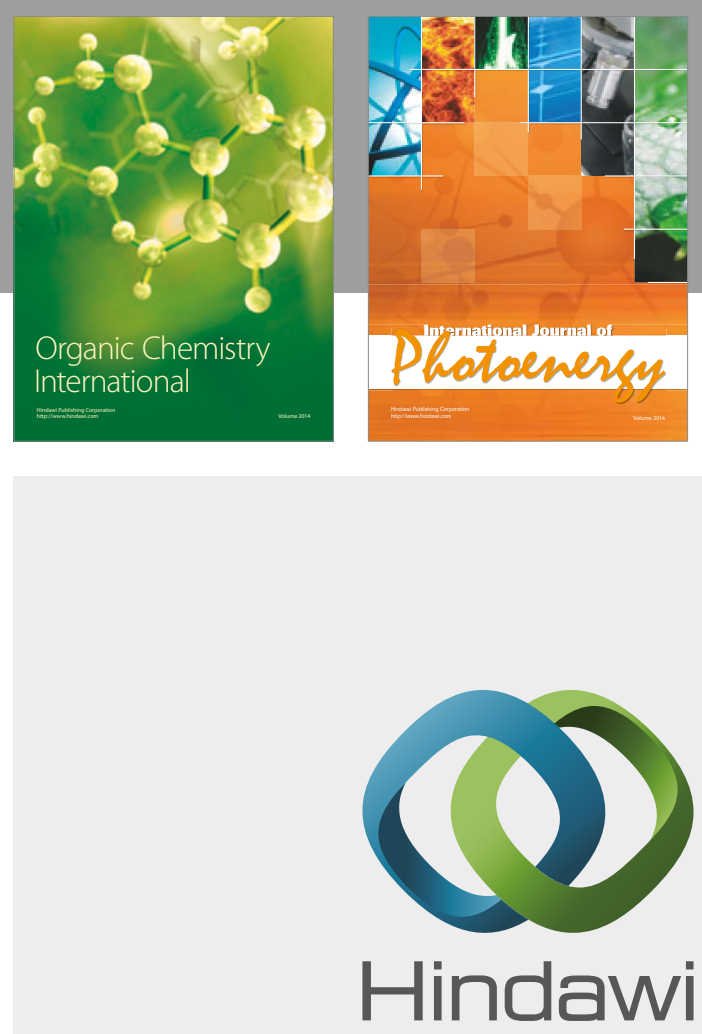

Submit your manuscripts at

https://www.hindawi.com

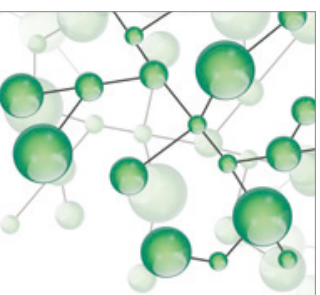

International Journal of

Inorganic Chemistry

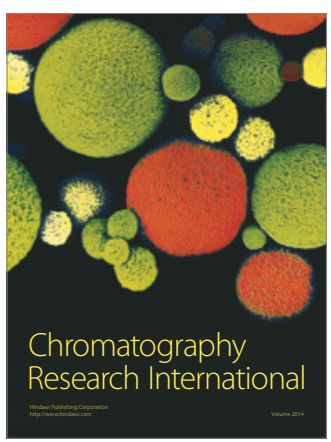

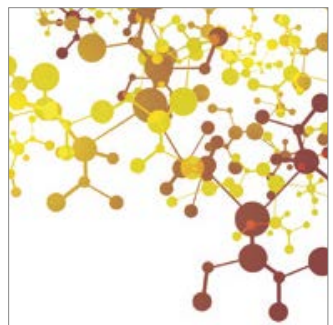

Applied Chemistry
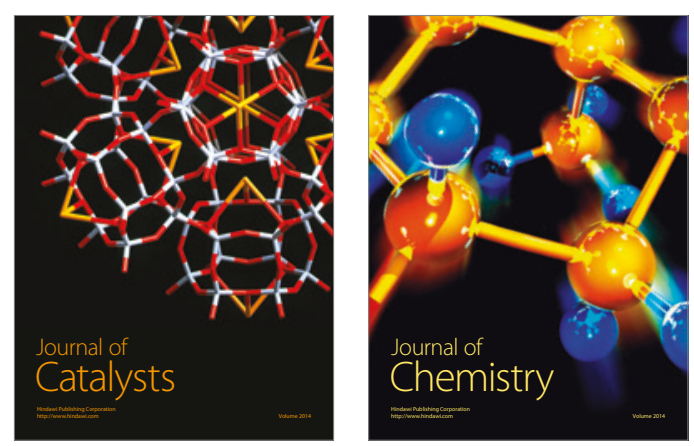
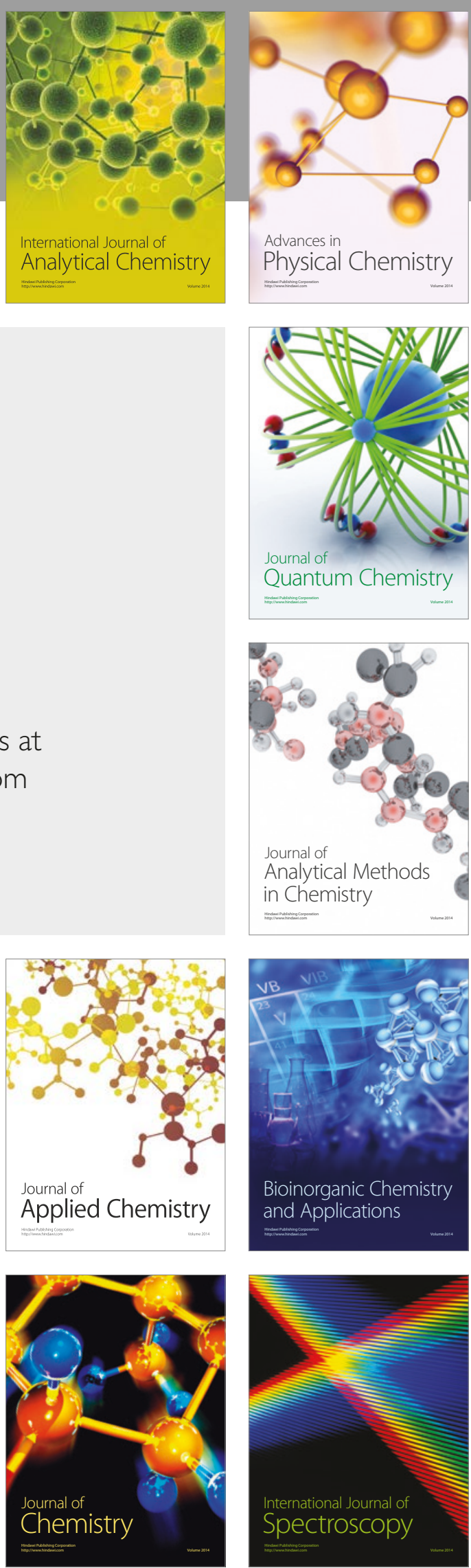